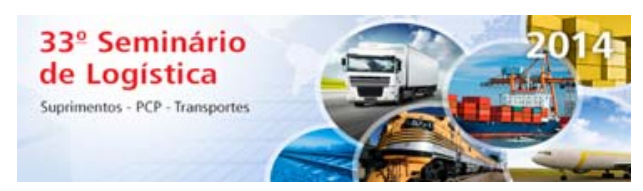

Tema: Gestão de Operações

\title{
OTIMIZAÇÃO DE EQUIPAMENTO RODOVIÁRIO NO TRANSPORTE DE CARVÃO VEGETAL DA VALLOUREC, VISANDO OTIMIZAÇÃO DE RECURSOS E COM GESTÃO DO PROCESSO VIA SAP*
}

\author{
André Luíz Moreira de Souza ${ }^{1}$ \\ Bruno de Carvalho Cevidanes ${ }^{2}$ \\ José Luiz de Souza ${ }^{3}$ \\ Luiz Otávio do Nascimento Ferreira ${ }^{4}$
}

Resumo

O objetivo do trabalho é demonstrar a otimização de recursos com a implantação de grades de agendamento e gestão logística via SAP do processo de abastecimento da Vallourec Tubos do Brasil, com carvão vegetal produzindo em fazendas da Vallourec unidade Florestal, distribuídas em quatro regionais no estado de Minas Gerais. O novo formato da operação permitiu a redução da frota utilizada e o aumento da taxa de ocupação dos equipamentos. Atualmente movimenta-se aproximadamente 400.000 ton./ano de carvão vegetal. A frota é composta por equipamentos novos, rastreados, transportadores dedicados, os quais são considerados parceiros no desenvolvimento da operação. Avalia-se o desempenho de cada equipe envolvida em frequentes reuniões, nas quais são definidas ações de melhoria sempre que necessárias. Temos um atendimento maior que $98 \%$ a grade programada para recebimento do carvão vegetal, considerando os tempos de carga e descarga.

Palavras-chave: Planejamento; Tecnologia da informação; Gestão custo; Segurança e satisfação cliente.

\section{OPTIMIZATION OF EQUIPMENT IN ROAD TRANSPORT CHARCHOAL VALLOUREC, TARGETING AND OPTIMIZATION WITH RESOURCES MANAGEMENT PROCESS VIA SAP} Abstract

The objective is to demonstrate the optimization of resources by deploying grids scheduling and logistics management via SAP Process supply of Vallourec Tubes from Brazil, with charcoal on farms producing unit of Vallourec Forest, divided into four regional state of Minas Gerais. The new format of the operation allowed the reduction of the fleet used and increased occupancy of equipment. Currently moves about 400,000 t. / Year of coal. The fleet consists of new equipment, tracked, dedicated carriers, which are considered partners in the development of the operation. Evaluates the performance of each team involved in frequent meetings where improvement actions are defined where necessary. We have a greater than $98 \%$ attendance scheduled to receive a grade of charcoal, considering the time of loading and unloading.

Keywords: Planning; Information technology; Management; Cost safety and customer satisfaction.

1 Graduado em logística, pós-graduado em Gestão de Custo Logística, Analista Logístico, Vallourec Florestal, Curvelo, MG, Brasil.

2 Administrador, controlador logístico da área de matérias-primas para produção de ferro gusa, Vallourec Tubos do Brasil, Belo Horizonte, MG, Brasil.

3 Técnico, coordenador técnico, gestão de contratos e administração da área de matérias-primas para produção de ferro gusa, Vallourec Tubos do Brasil, Belo Horizonte, Minas Gerais, Brasil.

4 Engenheiro metalúrgico, gerente de carbonização e logística, Vallourec Florestal, Curvelo, MG, Brasil.

* Contribuição técnica ao $33^{\circ}$ Seminário de Logística - Suprimentos, PCP, Transportes, 13 a 16 de maio de 2014, São Paulo, SP, Brasil. 


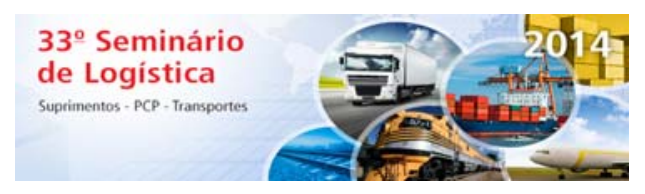

\section{INTRODUÇÃo}

Com as crescentes mudanças no cenário logístico, faz-se cada vez mais necessário a concretização de um bom gerenciamento na cadeia, fator indispensável na busca pela dinamização competitiva das empresas.

A velocidade necessária para tal adaptação no que se refere aos aspectos logísticos obriga as organizações a estarem mais ligadas a estas mudanças, bem como desenvolver alternativas que visam garantir sua sobrevivência ou sua primazia no mercado atual. Fleury [1] confirma e esclarece que "o mundo presenciou uma revolução nos conceitos, práticas e tecnologias logísticas, que contribuem decisivamente para o acelerado avanço da globalização".

Mediante estes aspectos e os entraves existentes é necessário ir além de todos estes conceitos previamente estabelecidos. Isto constitui que todos nós somos responsáveis por fazer esse processo fluir de forma simples, enxuta e ágil, adaptando-se de acordo com as necessidades operacionais e sem perder o foco no principal objetivo das operações logísticas que é atender e surpreender positivamente o cliente.

A busca por diferenciais cada vez mais competitivos necessita fortemente de esforços conjuntos entre os agentes envolvidos na cadeia logística. Métodos e ferramentas como gestão de relacionamento, otimização de transportes, ferramentas de qualidade total e bem estar social têm apresentado resultados positivos do ponto de vista da produtividade, da redução do tempo de espera e da satisfação dos motoristas, visando uma maior integração e melhoria contínua nos processos da Vallourec Tubos do Brasil S/A.

Realizar uma logística eficiente, utilizando os recursos com baixos níveis de ociosidade e, consequentemente, com um tempo de ciclo reduzido e atendendo aos requisitos legais e tendências de mercado é o desafio do presente trabalho.

\section{MATERIAL E MÉTODO}

\subsection{Vallourec Florestal Ltda.}

Fundada há 44 anos, a Vallourec unidade Florestal é subsidiária da Vallourec Tubos do Brasil S/A e responsável pelo abastecimento de carvão vegetal, principal fonte de energia renovável, utilizado nos Altos-Fornos da Usina Barreiro para produção de tubo de aço sem costura. O uso desse insumo na siderurgia resulta em importante benefício ambiental e faz com que a Vallourec unidade Florestal colabore com a redução da concentração de gases causadores do efeito estufa na atmosfera. Quando o $\mathrm{CO}_{2}$ é liberado no processo siderúrgico, ele é previamente absorvido da atmosfera pelas florestas plantadas de eucalipto, por meio da fotossíntese.

A sede administrativa da Vallourec unidade Florestal está localizada em Curvelo, região central de minas e possui, ainda, mais dois escritórios regionais nos municípios de João Pinheiro e Bocaiuva, regiões norte e noroeste do estado. Com cerca de 233 mil hectares de propriedades distribuídos em 22 fazendas, em 22 municípios mineiros, aproximadamente 113 mil hectares desse montante são florestas plantadas de eucaliptos. A área total de vegetação preservada, que contribui para a conservação da

* Contribuição técnica ao $33^{\circ}$ Seminário de Logística - Suprimentos, PCP, Transportes, 13 a 16 de maio de 2014, São Paulo, SP, Brasil. 


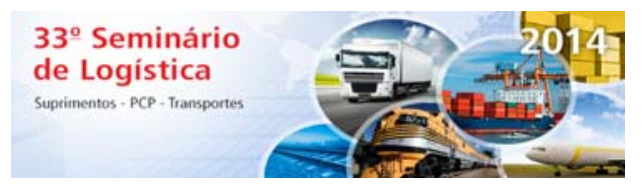

biodiversidade local, é de mais de 108 mil hectares que abrange as áreas de reserva legal, reservas espontâneas, veredas, faixas ecológicas, recurso hídrico, áreas de preservação permanente e outras áreas com cobertura vegetal nativa. O viveiro para a produção de mudas de eucalipto está localizado na cidade de Bocaiúva e produz cerca de 10 milhões de mudas clonais por ano, que abastecem todas as fazendas da empresa.

A Vallourec Unidade Florestal é uma das pioneiras no Brasil no plantio e no manejo de florestas de eucalipto, está na lista das empresas mais desenvolvidas tecnologicamente em seu setor de atividade. Na busca da qualidade e autossuficiência na produção de carvão, a Empresa desenvolve um programa de melhoramento genético por meio de pesquisas realizadas no Vallourec Centro de Competência Florestal, em Paraopeba (MG). Além do melhoramento genético, são realizados estudos sobre a qualidade da madeira, a proteção e a nutrição florestal. Com isso, é possível obter florestas de alta qualidade e produtividade aumento a qualidade do carvão.

O sistema produtivo é composto pelos seguintes processos: produção de mudas, preparo de área, plantio, manutenção florestal, colheita, carbonização e logística do abastecimento de carvão a Vallourec Tubos do Brasil. Todas as atividades operacionais são executadas com tecnologia própria, desenvolvida em parceria com centros de pesquisa brasileiros e internacionais.

A Vallourec unidade Florestal tem como visão ser uma empresa admirada pelas pessoas, sua missão é garantir o abastecimento de carvão vegetal para a Vallourec Tubos do Brasil e para a Vallourec \& Sumitomo Tubos do Brasil, com responsabilidade ambiental e social, qualidade e custo que viabilizem a competitividade do aço e tem como conduta a integridade e transparência, exigência e profissionalismo, performance e responsividade, respeito pelas pessoas e compromisso comum.

A Vallourec unidade Florestal conta atualmente, com mais de 2.600 empregados diretos e indiretos, sendo uma das maiores empregadoras da região.

O resultado da responsabilidade socioambiental pode ser comprovado pelas certificações conquistadas: ISO 14001, Certificação de Manejo Florestal (CERFLOR) e Certificação OHSAS 18001, que atestam que as atividades florestais Empresa estão ancoradas na sustentabilidade social, econômica e ambiental.

* Contribuição técnica ao 33o Seminário de Logística - Suprimentos, PCP, Transportes, 13 a 16 de maio de 2014, São Paulo, SP, Brasil. 

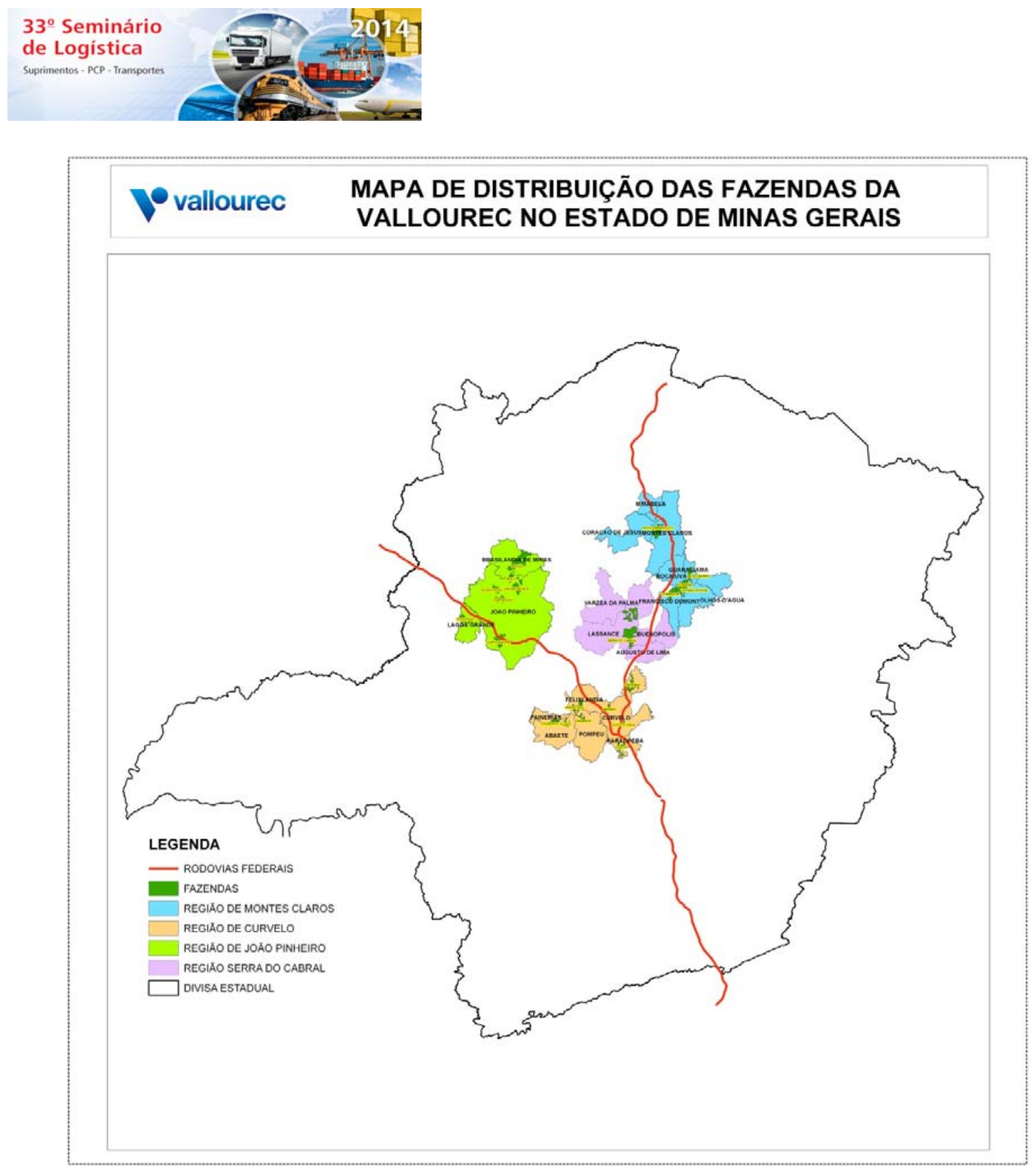

Figura 1. Visão Geral - Localização da Unidade florestal no estado de Minas Gerais.

\section{DESCRIÇÃO DO PROBLEMA}

Desenvolver um modelo logístico que possa ser gerenciado por um software de gestão oficial da empresa (SAP), com o objetivo de regular e cadenciar o tempo de entrega das cargas de carvão vegetal, diminuindo o fluxo de equipamentos, fazendo uma otimização do processo rodoviário, tendo com principal parâmetro de orientação para implementação de redução de equipamento e manter uma redução de estoque em trânsito. Reduzir o tempo médio de espera seja em carga ou descarga, gerar um valor representativo para os transportadores e, preferencialmente, manter um excelente atendimento à Vallourec unidade Tubos.

* Contribuição técnica ao 33o Seminário de Logística - Suprimentos, PCP, Transportes, 13 a 16 de maio de 2014, São Paulo, SP, Brasil. 


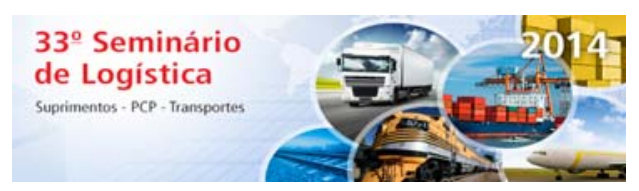

Existem fatores que não são controlados pelo modelo logístico estudado, tais como infraestrutura logística oferecida pelo país e questões sociais que também resultam na queda de produtividade.

As fases do tempo de ciclo que são controláveis também geram grandes impactos e podem ser otimizados, a fim de garantir melhor eficiência na cadeia com um todo.

\subsection{Fluxograma - Ciclo Logístico}

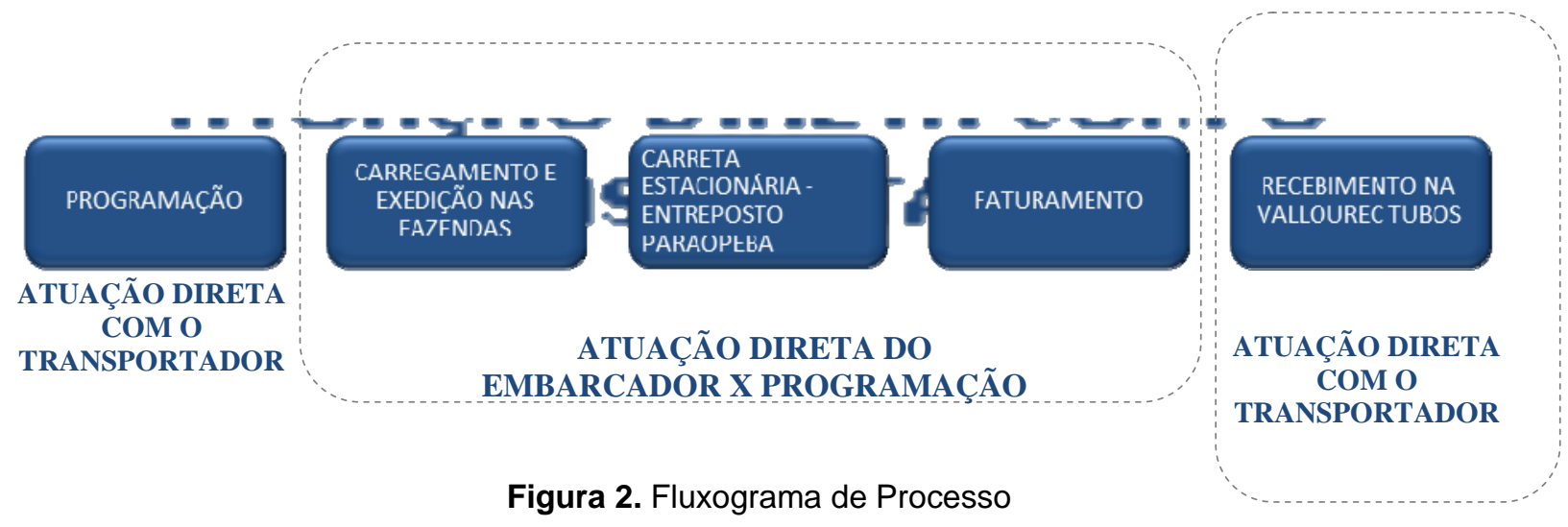

Baseados em estudos dos processos de negócio e de produtividade, análise de tempos e adequação de necessidades, somados a processos anteriormente desenvolvidos, que consiste em um sequenciamento de carga e janelas de carregamento nas fazendas, foi possível viabilizar neste cenário determinadas alternativas internas de redução do tempo de permanência dos veículos nas plantas de carbonização e entreposto, focados na minimização dos impactos e na eficiência operacional das entregas das carretas carregadas até o cliente. Paralelo a estas ações e considerando a Segurança como nosso maior valor, atuamos fortemente no desenvolvimento do processo de checagem dos veículos (check list) e oferecemos aos nossos parceiros o treinamento e conscientização dos motoristas.

\subsection{Planejamento}

Para o projeto de desenvolvimento do agendamento, o passo inicial foi obter uma melhor definição das particularidades das fazendas, entreposto e cliente, considerando suas características, analisando os impactos no final da linha de produção e as etapas de estocagem, carregamento, transporte e entrega ao cliente.

O planejamento é uma tarefa que pode levar algum tempo, mas foi essencial para a elaboração do projeto, a fim de se evitar alterações que possam gerar custos e uma possível perda de credibilidade do projeto com as partes envolvidas da cadeia.

\footnotetext{
* Contribuição técnica ao $33^{\circ}$ Seminário de Logística - Suprimentos, PCP, Transportes, 13 a 16 de maio de 2014, São Paulo, SP, Brasil.
} 


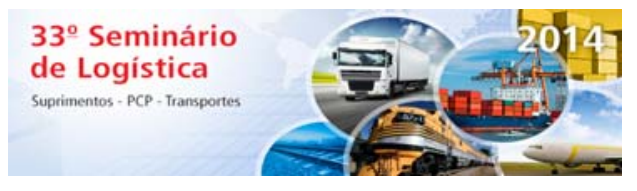

Yvallourec

\section{Agendament o de Carvão Vegetal}

\begin{tabular}{|c|c|c|c|c|c|c|c|c|c|}
\hline \multicolumn{10}{|c|}{ Programação de Carvão da UPC para a Usina } \\
\hline \multicolumn{4}{|c|}{ Programação a partir do dia »> } & \multicolumn{2}{|c|}{24 e $25 / 2$} & \multirow{2}{*}{\multicolumn{2}{|c|}{$\frac{\mathrm{N}^{0} \text { de Viagens } \gg}{\text { Usina (Barreiro) }}$}} & \multicolumn{2}{|c|}{11} \\
\hline \multirow{2}{*}{ Linha } & \multirow{2}{*}{ Empresa } & \multirow{2}{*}{ Fazenda } & \multicolumn{2}{|c|}{ UPC (Paraopeba) } & \multirow{2}{*}{ Viagem Ida } & & & \multirow{2}{*}{$\begin{array}{c}\text { Viagem } \\
\text { Volta }\end{array}$} & \multirow{2}{*}{$\begin{array}{c}\text { Chegada } \\
\text { UPC }\end{array}$} \\
\hline & & & Chegada & Saída & & Chegada & Saída & & \\
\hline 1 & Empresa $A$ & Patagonia & 11:00 & $11: 00$ & $02: 30$ & $13: 30$ & $14: 00$ & $02: 00$ & $16: 00$ \\
\hline 2 & Empresa $A$ & Chapadinha & $12: 00$ & $12: 00$ & $02: 30$ & $14: 30$ & $15: 00$ & $02: 00$ & $17: 00$ \\
\hline 3 & Empresa $B$ & Corredor & 18:00 & $18: 00$ & $02: 30$ & $20: 30$ & $21: 00$ & $02: 00$ & $23: 00$ \\
\hline 4 & Empresa A & Extrema & $21: 00$ & $21: 00$ & $02: 30$ & $23: 30$ & $00: 00$ & $02: 00$ & 02:00 \\
\hline 5 & Empresa $B$ & Extrema & $21: 30$ & $21: 30$ & $02: 30$ & $00: 00$ & $00: 30$ & $02: 00$ & $02: 30$ \\
\hline 6 & Empresa A & Extrema & $22: 00$ & $22: 00$ & $02: 30$ & $00: 30$ & $01: 00$ & $02: 00$ & 03:00 \\
\hline 7 & Empresa $B$ & Extrema & $22: 30$ & $22: 30$ & $02: 30$ & 01:00 & 01:30 & $02: 00$ & 03:30 \\
\hline 8 & Empresa C & Corredor & $23: 00$ & $23: 00$ & $02: 30$ & $01: 30$ & $02: 00$ & $02: 00$ & 04:00 \\
\hline 9 & Empresa B & Patagonia & $14: 00$ & $14: 00$ & $02: 30$ & $16: 30$ & $17: 00$ & $02: 00$ & $19: 00$ \\
\hline 10 & Empresa A & Pindaibas & $16: 00$ & $16: 00$ & $02: 30$ & $18: 30$ & 19:00 & $02: 00$ & $21: 00$ \\
\hline 11 & Empresa C & Campo Alegre & $18: 00$ & $18: 00$ & $02: 30$ & $20: 30$ & $21: 00$ & $02: 00$ & $23: 00$ \\
\hline
\end{tabular}

Figura 3. Agendamento de carvão vegetal.

\subsubsection{Benefícios}

O modelo logístico de otimização com Gestão no SAP teve uma importante participação na ampliação da produtividade operacional logística da Vallourec unidade Florestal, conforme abaixo:

- Redução dos Custos: alta produtividade e diminuição de hora parada;

- Qualidade: entrega das cargas intercaladas por dados técnico de qualidade;

- Confiabilidade: operação confiável e com menor número de erros;

- Agilidade: produção rápida;

- Flexibilidade: possibilidade de mudança.

* Contribuição técnica ao 33o Seminário de Logística - Suprimentos, PCP, Transportes, 13 a 16 de maio de 2014, São Paulo, SP, Brasil. 


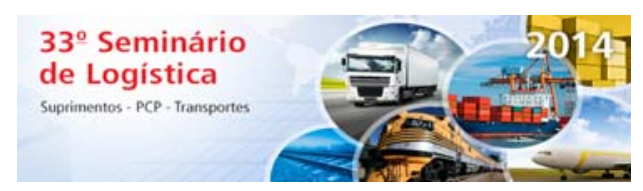

\subsection{Dados Operacionais - Tempos}

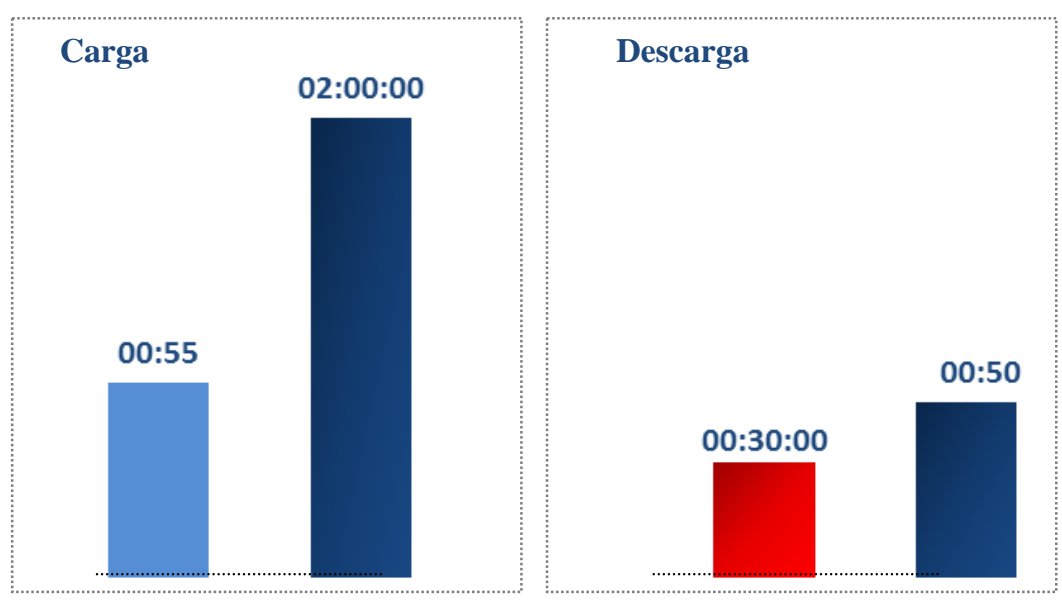

Figura 4. Controle de tempos - Carga e Descarga.

\subsection{Tempo Médio de Permanência Rodoviário}

Em todo processo logístico, um dos componentes cruciais de avaliação é o tempo, pois o mesmo é transformado em um custo que, no final do processo, irá interferir diretamente no preço, neste caso frete ou diárias. De acordo com Costa, Dias e Godinho [2] o tempo de transporte é um fator que apresenta grande relevância para os utilizadores do serviço e que, por muitas vezes, apresenta uma forte relação com o custo. Para Severo Filho [3] um dos objetivos da logística é a redução do tempo total de atendimento.

De acordo com a política de gestão de desempenho da Vallourec unidade Florestal, cada área dispõe de seus itens de controle, que é composto por indicadores operacionais e estratégicos que são medidos e acompanhados mensalmente por seus respectivos gestores. Baseado nos princípios de que ítens estratégicos são para reforçar a posição da organização no mercado, promovendo a satisfação dos clientes e o alcance dos objetivos de desempenho, tratamos e gerimos o Tempo de Permanência Veicular de uma maneira mais abrangente, definindo um conjunto de objetivos, finalidades, metas, diretrizes fundamentais e os planos para atingir os resultados postulados, de forma a definir em que situação o processo se encontra e qual o tipo de processo ele é ou deseja ser.

\section{CONCLUSÃO}

Hoje temos um modelo logístico cadenciado de entrega de carvão vegetal, gerenciado por um software de gestão logística, com um atendimento médio anual maior que $98 \%$ a necessidade logística da Vallourec unidade Tubos. A atividade que demandou maior atenção do grupo foi a de "criar", em todos os envolvidos no processo, uma preocupação em se ter uma base de informação técnica que represente a necessidade operacional dos Altos-Fornos. Ao término dessa etapa surgiu a necessidade de fazer a

* Contribuição técnica ao $33^{\circ}$ Seminário de Logística - Suprimentos, PCP, Transportes, 13 a 16 de maio de 2014, São Paulo, SP, Brasil. 


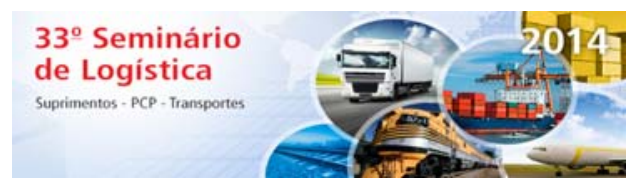

interação entre área técnica, contábil, programação e desenvolvimento de TI. Outra atividade de grande valor foi cadenciar as atividades e particularidades de cada processo envolvido, tratando as anormalidades e elaborando um plano único com desmembramento das ações por processo e interação do processo.

O resultado foi uma redução em $20 \%$ no valor total de frota disponível no processo de transporte de carvão vegetal da Vallourec unidade Florestal para a unidade Tubos, a segurança no cadenciamento de cargas, permitindo uma redução de estoque total e uma diminuição de $80 \%$ da movimentação do estoque de segurança. Com a necessidade de melhoria e segurança de informação todos os dados logísticos estão disponíveis em software de gestão oficial do grupo.

O resultado de maior importância para o grupo é a aproximação da unidade Florestal com a unidade Tubos.

\section{Agradecimentos}

Agradecemos a Deus por estarmos aqui, aos nossos parceiros pela confiança e crescimento técnico, ao grupo Vallourec pela oportunidade e confiança de nos mantermos a frente de um processo que, na gestão corporativa e nesse mercado globalizado, assume papel vital para sobrevivência de qualquer organização que queira se consolidar e se manter competitiva.

\section{REFERÊNCIAS}

1 Fleury PF. Logística e transportes. Jornal Valor Econômico. 2007;7(1673):A8.

2 Costa JP, Dias JM, Godinho P. Logística. Coimbra: Imprensa da Universidade de Coimbra; 2010.

3 Severo Filho J. Administração de logística integrada - Materiais, PCP e Marketing. $2^{\mathrm{a}}$ ed. Rio de Janeiro: E-papers; 2006.

\section{BIBLIOGRAFIA}

1 Novaes AG. Logística e gerenciamento da cadeia de distribuição: estratégia, operação e avaliação. Rio de Janeiro: Campus; 2001.

2 Bowersox DJ, Closs DJ. Logística empresarial: o processo de integração da cadeia de suprimento. São Paulo: Atlas; 2001.

* Contribuição técnica ao $33^{\circ}$ Seminário de Logística - Suprimentos, PCP, Transportes, 13 a 16 de maio de 2014, São Paulo, SP, Brasil. 